\title{
Social isolation due to the COVID-19 pandemic has led to worse outcomes in females with inflammatory arthritis
}

\author{
Sinead Maguire ${ }^{1}$ (D) Finbar $\mathrm{O}^{\prime}$ Shea $^{1}$ \\ Received: 29 June 2020 / Accepted: 5 July 2020 / Published online: 12 July 2020 \\ (C) Royal Academy of Medicine in Ireland 2020
}

\begin{abstract}
Background Prolonged social isolation as a result of the COVID-19 global pandemic has been a source of considerable psychological distress for many people. This can manifest in many ways and if left undetected can impact negatively on general health. It is essential to understand the impact of these conditions on inflammatory arthritis (IA) patients, especially axial spondyloarthropathy (axSpA).

Aim To capture the level of psychological distress for patients with IA following prolonged social isolation.

Methods A survey was sent out to patients with a confirmed diagnosis of IA. This captured changes in sleep, mood, disease activity, employment and general health since the beginning of the social isolation period. A PHQ-4 (Patient Health Questionnaire) was included to determine level of psychological distress.

Results Females with IA reported significantly higher rates of decline in general health $(40 \%$ vs $16 \%, p=0.01)$, mood disturbance $(43.4 \%$ vs $26 \%, p=0.03)$ and increased disease activity $(50 \%$ vs $16 \%, p=0.01)$ compared to males. Evaluating the mean PHQ-4 scores, no significant difference was noted between genders ( 4.80 vs $3.44, p=0.10)$. However, females demonstrated a non-significant trend toward increased rates of moderate to severe psychological distress ( $40 \%$ vs $30 \%, p=0.13)$. Subanalysis of patients with axSpA found high rates of moderate to severe distress in both genders.

Conclusions Females with IA reported significantly higher rates of decline in general health, mood disturbance and increased disease activity during the period of social isolation. This was reflected in a trend towards greater levels of psychological distress.
\end{abstract}

Keywords Arthritis $\cdot$ COVID-19 $\cdot$ Females $\cdot$ Isolation $\cdot$ Psychological distress

\section{Introduction}

Quarantine and social isolation are public health measures used to contain and prevent the spread of an infectious disease [1]. Throughout human history, a number of infectious diseases have required periods of quarantine to prevent widespread illness and death. Use of these measures were first described in Venice due to the Black Plague, with more recent mandated quarantines for the SARS and Ebola outbreaks [2]. The COVID-19 pandemic is unprecedented in many ways, with almost 4 billion of the world's population required to live in social isolation. In Ireland, and much of the EU, the social isolation has now gone on for over 3 months. Although

Sinead Maguire

sinead.magu@gmail.com

1 Department of Rheumatology, St James' Hospital, Dublin, Ireland restrictions are slowly being lifted, it is expected that social distancing and normal life as we know it will not be able to resume until a vaccine is widely available.

This prolonged period of social isolation has affected multiple aspects of everyday living. These disruptions have the potential for far reaching effects if not identified and addressed promptly. During this time, a number of households are under significant financial strain, without childcare, working from home and managing remote education for children. These new challenges in addition to concerns around COVID-19 infection and transmission could lead to significant psychological distress.

Given the setting of a global pandemic, some distress is to be anticipated. However, cases of extreme psychological distress, if left unrecognized, can impact both general health in addition to significantly affecting long-term mental health. It is essential to identify patients at high risk of developing severe psychological distress and address the triggers when possible. 
Table 1 Overall outcomes by gender

\begin{tabular}{|c|c|c|c|}
\hline & Males & Females & $p$ value \\
\hline$n$ & $62.5 \%(50)$ & $37.5 \%(30)$ & \\
\hline Age & 50.1 & 50.5 & 0.91 \\
\hline General health & & & 0.01 \\
\hline Improved & $20 \%(10)$ & $30 \%(9)$ & \\
\hline No change & $64 \%(32)$ & $30 \%(9)$ & \\
\hline Worsened & $16 \%(8)$ & $40 \%(12)$ & \\
\hline Sleep quality & & & 0.2 \\
\hline Improved & $12 \%(6)$ & $10 \%(3)$ & \\
\hline No change & $68 \%(34)$ & $43.4 \%(13)$ & \\
\hline Worsened & $20 \%(10)$ & $43.4 \%(13)$ & \\
\hline Mood & & & 0.03 \\
\hline Improved & $8 \%(4)$ & $26.7 \%(8)$ & \\
\hline No change & $64 \%(32)$ & $30 \%(9)$ & \\
\hline Worsened & $26 \%(13)$ & $43.4 \%(13)$ & \\
\hline Disease activity & & & 0.01 \\
\hline Improved & $10 \%(5)$ & $20 \%(6)$ & \\
\hline No change & $70 \%(35)$ & $30 \%(9)$ & \\
\hline Worsened & $16 \%(8)$ & $50 \%(15)$ & \\
\hline Weekly exercise & & & 0.26 \\
\hline Increased & $26 \%$ & $43.4 \%(13)$ & \\
\hline No change & $44 \%(22)$ & $33.3 \%(10)$ & \\
\hline Decreased & $30 \%(15)$ & $23.3 \%(7)$ & \\
\hline Self-isolation companions & & & 0.16 \\
\hline Alone & $22 \%(11)$ & $10 \%(3)$ & \\
\hline Family or partner & $76 \%(38)$ & $90 \%(27)$ & \\
\hline Currently employed & & & 0.55 \\
\hline Yes & $42 \%(21)$ & $53.3 \%(16)$ & \\
\hline No & $58 \%(29)$ & $46.7 \%(14)$ & \\
\hline Unemployed due to COVID-19 & $22 \%(11)$ & $16.7 \%(5)$ & 0.49 \\
\hline Work location & & & 0.54 \\
\hline Home & $16 \%(8)$ & $33.3 \%(10)$ & \\
\hline On site & $20 \%(10)$ & $13.3 \%(4)$ & \\
\hline Other & $4 \%(2)$ & $6.7 \%(2)$ & \\
\hline Engagement with patient support group & $4 \%(2)$ & $3.3 \%(1)$ & 0.25 \\
\hline
\end{tabular}

Inflammatory arthritis (IA) refers to systemic autoimmunemediated diseases affecting the joints. Patients with this type of diagnosis commonly require lifelong medication to decrease inflammation, manage symptoms and prevent progression of disease. Regular exercise and stretching is also an essential component of management. Axial spondyloarthropathy (axSpA) is a form of IA affecting the sacroiliac joints and the spine [3]. Patients with axSpA have been previously shown to have increased rates of depression [4] and there is a trend towards higher levels of disease activity in patients with depression [5]. For this reason, it is essential to understand the impact of the COVID-19 pandemic on axSpA patients, in order to address their needs and concerns in the months to come. The aims of this study are to capture the level of psychological distress for patients with inflammatory arthritis and understand how this is affecting their disease and general health.

\section{Methods}

\section{Study design}

A survey was distributed in May 2020, to patients attending the department of Rheumatology in St James' Hospital. Eligible patients were over the age of 18, fluent in English and had a confirmed diagnosis of inflammatory arthritis 
60

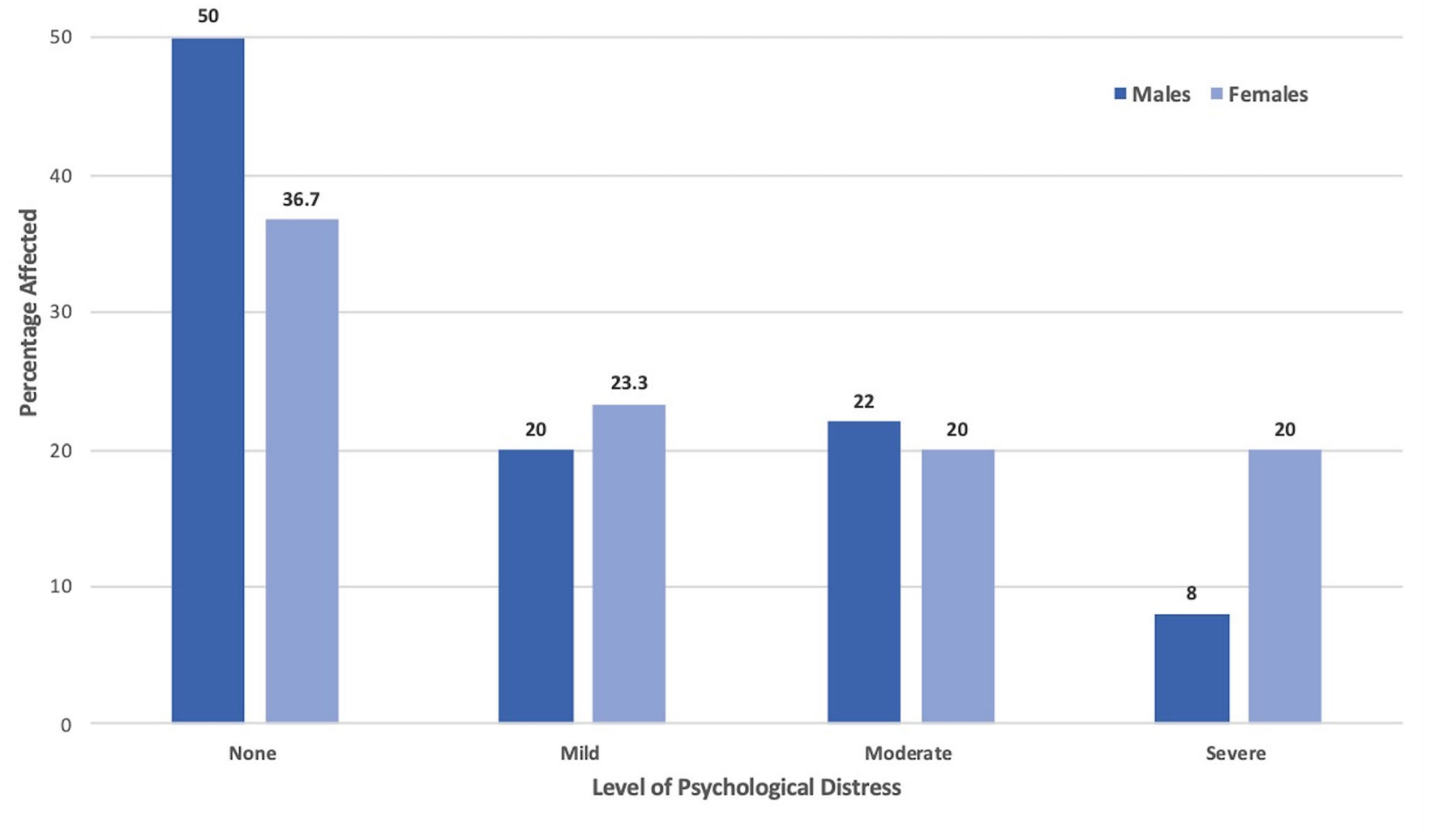

Fig. 1 PHQ-4 outcomes by gender

including axSpA. Participation was voluntary. Results of the survey were analysed on the basis of gender and diagnosis.

The survey captured information on changes in sleep, mood, disease activity, exercise, employment and general health since the beginning of the social isolation period. Changes were quantified as improved, no change or worsened.

A PHQ-4 (Patient Health Questionnaire) was included to determine level of psychological distress. This four-question tool generates a numerical result corresponding with the following levels of psychological distress: $0-2=$ none, $3-5=$ mild, 6-8 = moderate, 9-12= severe. To capture level of social interaction, patients were asked if they were in isolation with other people or alone. For patients who were employed, they were asked if they were working remotely or on site.

\section{Data analysis}

Analysis was performed using IBM SPSS version 26. An independent sample $t$ test was used to test for significance in differences of means between groups, including age and PHQ-4 scores. A $\mathrm{Chi}^{2}$ test for independence was used to test categorical variables. A $p$ value of $<0.05$ was deemed significant. PHQ-4 scores were tested by mean overall scores and prevalence of each category between comparison groups.

\section{Results}

In total, 88 completed surveys were returned, of these 80 contained data on gender and were included in this analysis. Patients were $37.5 \%$ (30) females and 62.5\% (50) males with a mean age of 50.7 years (Table 1). Population was predominantly axSpA patients, $73.8 \%$ (59) with $26.3 \%$ (21) patients with inflammatory arthritis. Fifty percent (40) were currently employed; of this, $47.5 \%$ (19) of patients were working from home. Of the $54.5 \%$ (48) of patients who were unemployed, $35 \%$ (17) had become unemployed since the covid-19imposed shutdowns began. Mean PHQ-4 score was 4.10, corresponding with a level of mild psychological distress. Analysis of patients by diagnosis revealed no significant differences in outcome measures between IA and axSpA. Patients with IA were noted to be older that axSpA patients (57.9 vs 48.3, $p=0.02$ ).

Eighty responses contained data on gender. Overall, females reported significantly higher rates of mood disturbance $(43.4 \%$ 
Table 2 Outcomes in AxSpA by gender

\begin{tabular}{|c|c|c|c|}
\hline & Males & Females & $p$ value \\
\hline$n$ & $69.5 \%(41)$ & $30.5 \%(18)$ & \\
\hline Age & 49.6 & 45.6 & 0.36 \\
\hline General health & & & 0.02 \\
\hline Improved & $19.5 \%(8)$ & $27.7 \%(5)$ & \\
\hline No change & $63.4 \%(26)$ & $22.2 \%(4)$ & \\
\hline Worsened & $17.1 \%(7)$ & $50 \%(9)$ & \\
\hline Sleep quality & & & 0.18 \\
\hline Improved & $9.7 \%(4)$ & $16.7 \%(3)$ & \\
\hline No change & $70.1 \%(29)$ & $38.9 \%(7)$ & \\
\hline Worsened & $19.5 \%(8)$ & $44.4 \%(8)$ & \\
\hline Mood & & & 0.1 \\
\hline Improved & $7.3 \%(3)$ & $27.7 \%(5)$ & \\
\hline No change & $63.4 \%(26)$ & $27.7 \%(5)$ & \\
\hline Worsened & $26.8 \%(11)$ & $44.4 \%(8)$ & \\
\hline Disease activity & & & 0.04 \\
\hline Improved & $7.3 \%(3)$ & $22.2 \%(4)$ & \\
\hline No change & $73.2 \%(30)$ & $27.7 \%(5)$ & \\
\hline Worsened & $17.1 \%(7)$ & $50 \%(9)$ & \\
\hline Weekly exercise & & & 0.26 \\
\hline Increased & $22 \%(9)$ & $44.4 \%(8)$ & \\
\hline No change & $46.3 \%(19)$ & $27.7 \%(5)$ & \\
\hline Decreased & $31.7 \%(13)$ & $27.7 \%(5)$ & \\
\hline Self-isolation companions & & & 0.09 \\
\hline Alone & $22 \%(9)$ & $5.6 \%(1)$ & \\
\hline Family or partner & $75.6 \%(31)$ & $94.4 \%(17)$ & \\
\hline Currently employed & & & 0.73 \\
\hline Yes & $46.3 \%(19)$ & $55.6 \%(10)$ & \\
\hline No & $53.7 \%(22)$ & $44.4 \%(8)$ & \\
\hline Unemployed due to covid-19 & $19.5 \%(8)$ & $27.7 \%(5)$ & 0.13 \\
\hline Work Location & & & 0.54 \\
\hline Home & $17.1 \%(7)$ & $38.9 \%(7)$ & \\
\hline On site & $22 \%(9)$ & $11.1 \%(2)$ & \\
\hline Other & $4.9 \%(2)$ & $5.6 \%(1)$ & \\
\hline Engagement with patient support group & $2.4 \%(1)$ & $5.6 \%(1)$ & 0.75 \\
\hline
\end{tabular}

vs $26 \%, p=0.03)$ and increased disease activity (50\% vs $16 \%$, $p=0.01$ ) compared to males (Table 1). Females also reported high rates of decline in general health $(40 \%$ vs $16 \%, p=0.01)$. No differences were detected in sleep quality or weekly exercise. Similar rates of employment were noted in both groups.

No significant difference was detected in mean PHQ-4 scores or distribution or level of psychological distress; however, females demonstrated a non-significant trend towards higher rates of severe distress $(20 \%$ vs $8 \%, p=0.13)$ (Fig. 1).

Further analysis focused on axSpA patients alone on the basis of gender. Of the 59 axSpA patients included in the analysis, $30.5 \%$ (18) were female and $69.5 \%$ (41) male (Table 2). AxSpA females had higher rates of decline in general health $(50 \%$ vs $17.1 \%, p=0.02)$ and increased disease activity (50\% vs $17 \%, p=0.04)$ compared to axSpA males. Although axSpA females had increased rates of mood disturbance $(44.4 \%$ vs $26.8 \%, p=0.1)$, this did not reach significance.

No significant difference was noted in mean PHQ-4 scores (4.78 vs 3.44, $p=0.18$ ) or level of psychological distress, but axSpA females demonstrated a non-significant trend towards higher rates of psychological distress than males (Fig. 2).

\section{Discussion}

The COVID-19 global pandemic led to an abrupt and prolonged period of social isolation to stem spread of the 
60

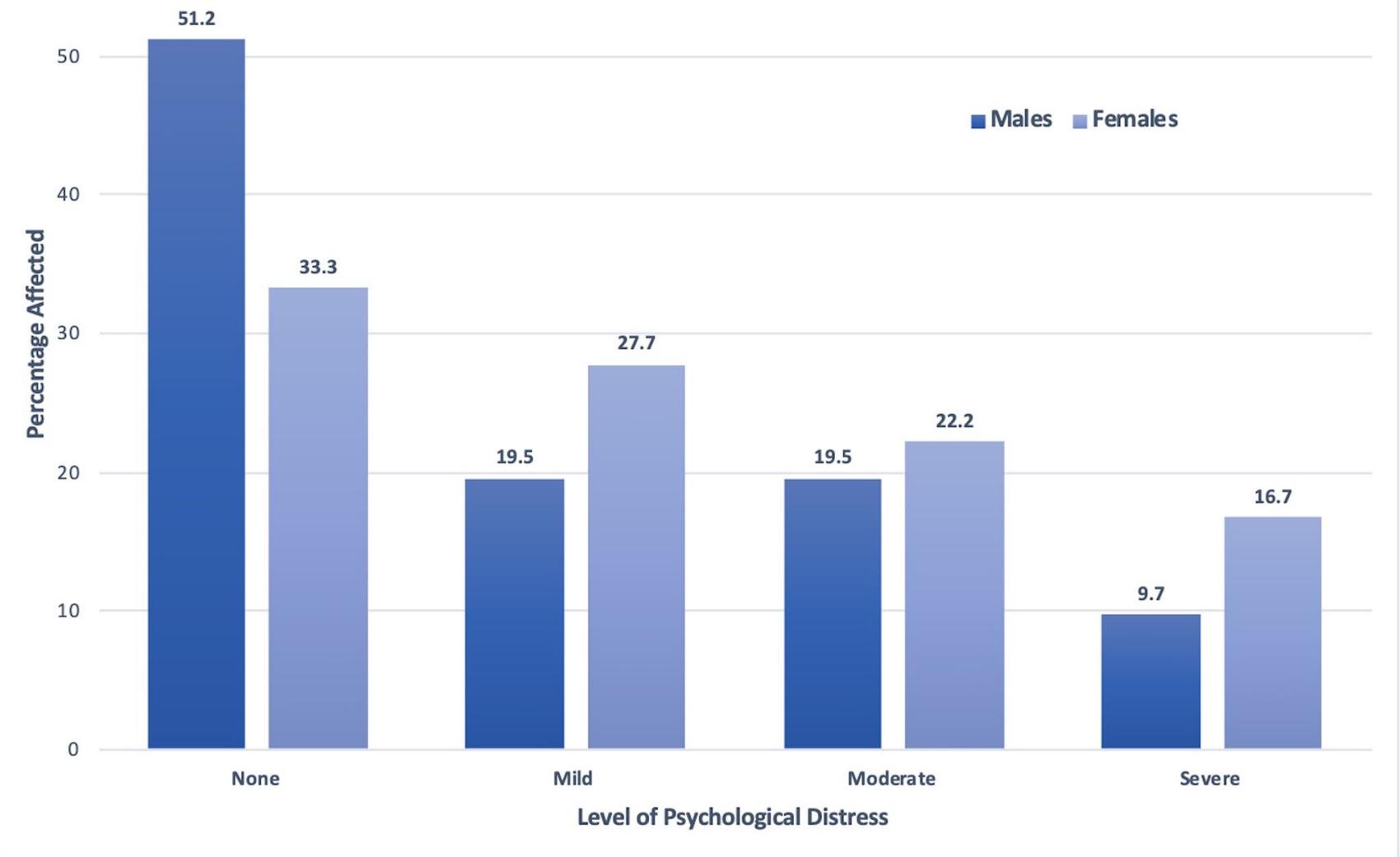

Fig. 2 PHQ-4 outcomes in AxSpA by gender

virus. This analysis demonstrates the significant effect of these lifestyle changes on patients with inflammatory arthritis. Use of the PHQ-4 allowed for quantification of the level of psychological distress during this time with over 59\% of patients surveyed reporting some level of distress. Females reported high levels of decline in general health, mood disturbance and increased disease activity. This is reflected in higher mean PHQ-4 scores and increased rates moderate to severe psychological distress in females compared to males. Subgroup analysis of the axSpA patients alone reached demonstrated similar findings but did not reach significance in variation of mood disturbance.

Previous studies have shown that prolonged social isolation can lead to decreased work performance and increased risk of mental health disorders [6]. Addressing the issues identified in this analysis will require considerable time, education and energy from clinicians. Recognising those most affected is only the first step in aiding recovery. The WHO has encouraged healthcare workers to be familiar with resources available to support patients requiring psychosocial support [7]. Encouraging regular exercise [8], increased reliance on digital communication [9] and social integration [10] are strategies proposed to decreased psychological distress under current restrictions.

It is unclear why disease activity and general health outcomes are worse in females than males. One potential contributing factor is the increased rates of females working from home, while males more commonly worked on site. Females also reported higher rates of sleep disturbance which did not reach significance but could be contributory. Discussion with individual patients to identify potential causes of distress would provide further insight into this issue.

As this study was conducted via mail survey with an overall response rate of $44 \%$, a potential limitation of the study was nonresponse bias. However, the sample respondent groups were highly representative of both patient populations surveyed in terms of age and gender, which has been shown to decrease the risk of nonresponse bias $[11,12]$.

This analysis demonstrates that the impact of the pandemic extends beyond physical well-being and disease activity. Prompt recognition of psychological distress and other effects of prolonged social isolation will help in managing patients going forward. 
Acknowledgements We thank the patients for participating in this study.

Authors' contributions All authors contributed to the study concept and design. Data collection, analysis and manuscript composition was performed by all authors. All authors read and approved final version of the manuscript prior to submission.

Data availability Anonymized data available upon request.

\section{Compliance with ethical standards}

Conflict of interest The authors declare that they have no conflict of interest.

Ethics approval Project was reviewed and approved by the St James' Hospital/Tallaght University Hospital Joint Research Ethics Committee.

Consent to participate Participation in the survey following review of the patient information leaflet was taken as implied consent. Participation in the study was voluntary.

Consent for publication Prior to participation in this study, all patients were provided with an information leaflet detailing how results would be published in a medical journal. As stated within this leaflet, participation implied consent for publication.

\section{References}

1. Giubilini A, Douglas T, Maslen H, Savulescu J (2018) Quarantine, isolation and the duty of easy rescue in public health. Dev World Bioeth 18(2):182-189. https://doi.org/10.1111/dewb.12165

2. Barbisch D, Koenig KL, Shih FY (2015) Is there a case for quarantine? Perspectives from SARS to Ebola. Disaster Med Public Health Prep 9(5):547-553. https://doi.org/10.1017/dmp.2015.38
3. Zhu W, He X, Cheng K et al (2019) Ankylosing spondylitis: etiology, pathogenesis, and treatments. Bone Res 7:22. https://doi.org/ 10.1038/s41413-019-0057-8

4. Park JY, Howren AM, Zusman EZ et al (2020) The incidence of depression and anxiety in patients with ankylosing spondylitis: a systematic review and meta-analysis. BMC Rheumatol 4:12. https://doi.org/10.1186/s41927-019-0111-6

5. Webers C, Vanhoof L, Leue C et al (2019) Depression in ankylosing spondylitis and the role of disease-related and contextual factors: a cross-sectional study. Arthritis Res Ther 21(1):215. https:// doi.org/10.1186/s13075-019-1995-7

6. Torales J, O'Higgins M, Castaldelli-Maia JM, Ventriglio A (2020) The outbreak of COVID-19 coronavirus and its impact on global mental health. Int J Soc Psychiatry 66(4):317-320. https://doi.org/ 10.1177/0020764020915212

7. World Health Organisation (2020) Mental health and psychosocial considerations during the COVID-19 outbreak. WHO

8. Matias FDT, Marks DF (2020) Human needs in COVID-19 isolation. J Health Psychol 25(7):871-882. https://doi.org/10.1177/ 1359105320925149

9. Razai MS, Oakeshott P, Kankam H et al (2020) Mitigating the psychological effects of social isolation during the covid-19 pandemic. BMJ 369:m1904. https://doi.org/10.1136/bmj.m1904

10. Banerjee D, Rai M (2020) Social isolation in Covid-19: the impact of loneliness. Int J Soc Psychiatry 20764020922269. https://doi. org/10.1177/0020764020922269

11. Research AAfPO Response Rates - An Overview

12. Phillips AW, Reddy S, Durning SJ (2016) Improving response rates and evaluating nonresponse bias in surveys: AMEE Guide No. 102. Med Teach 38(3):217-228. https://doi.org/10.3109/0142159x. 2015.1105945

Publisher's note Springer Nature remains neutral with regard to jurisdictional claims in published maps and institutional affiliations. 